\title{
Marco teórico para un análisis integral de los derechos humanos y fundamentales
}

Theoretical framework for a comprehensive analysis of human and fundamental rights

Autor: William J. Parra

DOI: https://doi.org/10.19053/16923936.v18.n35.2020.10167

Para citar este artículo:

Parra, W. (2020). Marco teórico para un análisis integral de los derechos humanos y fundamentales. Revista Derecho y Realidad, 18, (35), 105- 127. 


\title{
MARCO TEÓRICO PARA UN ANÁLISIS INTEGRAL DE LOS DERECHOS HUMANOS Y FUNDAMENTALES
}

\author{
Theoretical framework for a comprehensive analysis of human and fundamental rights \\ Enquadramento teórico para uma análise abrangente dos direitos humanos e \\ fundamentais
}

\author{
William J. Parra \\ Abogado. Especialista en derecho penal y Auditoría Forense \\ Investigador y docente de la Universidad Padagógica y Tecnológica de Colombia \\ williamj.parra@gmail.com
}

Recepción: 17 de noviembre 2019

Aceptación: 7 de julio 2020

\section{RESUMEN}

Este trabajo tiene como objetivo mostrar que la construcción del marco teórico de los derechos humanos ha girado en torno a cuatro grandes categorías de análisis: el concepto, la fundamentación, la materialización y las responsabilidades por la protección y vulneración de los mismos. Sin embargo, desde hace más de una década, se están priorizando los estudios dirigidos a la construcción y solución de los problemas sociales prácticos, los cuales afectan los derechos fundamentales, sociales y colectivos. Por otro lado, las actividades de los grupos de investigación y las organizaciones de defensores de derechos humanos confluyen en la necesidad de aplicar la investigación- acción y el desarrollo de medios y estrategias para materializarlos mediante el litigio estratégico constitucional y legal, así como mediante propuestas de políticas públicas.

\section{PALABRAS CLAVES}

Derechos humanos y fundamentales; concepto; fundamentación; materialización; responsabilidades; investigación/acción; políticas públicas.

\section{ABSTRACT}

The objective of this work was to show that the construction of the theoretical framework of human rights has revolved around four main categories of analysis: the concept, the foundation, the materialization and the responsibilities for the protection and violation of the same. However, for more than a decade, studies aimed at the construction and solution of practical social problems, which affect fundamental, social and collective rights, have been prioritized. On the other hand, the activities of research groups and organizations of human rights defenders converge in the need to apply 
action research and the development of means and strategies to materialize them through strategic constitutional and legal litigation, as well as through proposals of public policies.

\section{KEYWORDS}

Human and fundamental rights, concept, foundation, materialization, responsibilities, research / action, public policies.

\section{RESUMO}

O objetivo deste trabalho foi mostrar que a construção do enquadramento teórico dos direitos humanos girou em torno de quatro categorias principais de análise: o conceito, o fundamento, a materialização e as responsabilidades pela proteção e violação dos mesmos. No entanto, há mais de uma década, estudos voltados à construção e solução de problemas sociais práticos, que afetam direitos fundamentais, sociais e coletivos, têm sido priorizados. Por outro lado, as atividades de grupos de pesquisa e organizações de defensores de direitos humanos convergem na necessidade de aplicar a pesquisa-ação e o desenvolvimento de meios e estratégias para materializá-las por meio de litígios constitucionais e legais estratégicos, bem como por propostas de políticas públicas.

\section{PALAVRAS-CHAVE:}

Direitos humanos e fundamentais, conceito, fundamento, materialização, responsabilidades, pesquisa / ação, políticas públicas.

\section{INTRODUCCIÓN}

Hace varias décadas, Norberto Bobbio (1991, p. 64) llamó la atención sobre cómo muchos análisis filosóficos, jurídicos, sociológicos y antropológicos se concentraron en desarrollar el concepto teórico de los derechos humanos y su fundamentación, lo cual enriqueció su perspectiva filosófica e ideal pero, en detrimento de su practicidad, la protección efectiva $y$ el trabajo con personas $y$ comunidades afectadas.

Acatando dicho señalamiento, se han incorporado reflexiones y acciones que, sin descuidar la reflexividad filosófica, se orientan en la protección efectiva, la materialización y el análisis de las responsabilidades en áreas muy complejas y prácticas como la ciencia, las nuevas tecnologías, la sociedad virtual, las políticas públicas, las actividades de las empresas multinacionales, el manejo de los recursos públicos, la corrupción, la globalización económica, la alimentación, el Internet, la Inteligencia Artificial (IA), entre otras.

Se advierte además que en esos escenarios sociales están surgiendo nuevas dimensiones analíticas en las cuales se ajustan las cuatro categorías fundamentales de los derechos humanos y fundamentales, con el fin de adaptarlas a la compleja y acelerada transformación social. Dichos estudios integrales se concentran especialmente en la construcción y solución de los problemas jurídicos de los derechos humanos, fundamentales, sociales $\mathrm{y}$ colectivos.

A continuación se presentará la evolución de las categorías fundamentales en el análisis de los derechos humanos. En primer lugar, se mostrará cómo el concepto de derechos humanos, sin perder su idealidad o la dimensión metafísica relacionada con la protección de la persona humana, también se orienta hacía una conceptualización más material y práctica de las necesidades. En segundo lugar, se verá que, en ámbitos sociales como la Internet, la protección de datos, la genética y otros escenarios muy complejos, se están diseñando nuevas fundamentaciones o razones sobre por qué allí existen realidades de derechos humanos y fundamentales que han de ser construidas, reconocidas y protegidas.

En tercer lugar, se evidencia que la materialización de los derechos humanos ha superado la consagración meramente normativa de los derechos humanos $y$ fundamentales (tratados, constitución, 
ley), y ha pasado a ser parte de las políticas públicas, de las decisiones de las mismas empresas y de quienes toman decisiones concretas que pueden afectar o afirmar estos derechos. En cuarto lugar, se expondrá que las responsabilidades concretas por la protección, así como por la vulneración se plantean desde lo civil, lo administrativo y lo penal.

Finalmente, planteamos que en la investigación académica es muy importante tener en cuenta estos cambios teóricos y prácticos con el fin de aplicarlos en la investigación acción, en el litigio estratégico (constitucional y legal) y en la formulación de políticas públicas dirigidas a plantear soluciones a los problemas de los derechos fundamentales, sociales y colectivos.

\section{QUÉ SON LOS DERECHOS HUMANOS (CONCEPTO)}

Existen múltiples definiciones de los derechos humanos, los cuales contienen diversos enfoques ideológicos, filosóficos, jurídicos, teológicos, del derecho internacional público, sociológicos, económicos, entre otros. Uprimny considera, al respecto, que no es posible construir un concepto único que contenga las diferentes concepciones ideales y prácticas, por tanto, es menester reconocer y distinguir las diferentes perspectivas filosóficas y normativas en las que es utilizado este concepto (Uprimny, 2006, p.10).

Uno de los usos más característicos de este concepto se hace desde la perspectiva ideal o como categoría metafísica, moral y racional, inherente a la existencia y la naturaleza de los hombres, esto es, como principios que tienen características especiales porque son anteriores y superiores al orden o contrato social y las normas que los rigen. En esa medida, sirve como una meta el concepto que advierte que las normas sociales, construidas por los hombres, deben estar en concordancia con esos principios que trascienden a los sistemas político, jurídico o económico (Cfr. Hart, 1955; Alexy 1995).

Sin embargo, también es utilizado en la dimensión normativa y en varios sentidos: el primero es como una categoría ética, la cual rige la convivencia social entre las personas y que además pueden ser exigidas tanto a las instituciones del Estado como por los particulares y cuya finalidad es la protección de la dignidad de la persona. El segundo es, como categoría del derecho internacional, público (tratados) en donde se establecen deberes negativos y positivos para los Estados y, en caso de incumplimiento, el Estado puede ser hallado responsable de la violación de estos derechos.

En esta medida, estos se consideran un conjunto de normas e instancias internacionales que complementan los mecanismos estatales de derechos fundamentales, los cuales pueden ser utilizados cuando estos han fallado y no se encuentran otros recursos de protección en el nivel interno. En tercer lugar, como categoría del derecho interno, los derechos humanos han sido incorporados en los ordenamientos constitucionales y legales estatales, es decir, son derechos constitucionales de tres tipos: derechos fundamentales, derechos sociales y derechos colectivos. La diferencia entre ellos está en el reforzamiento de su protección y en las garantías y los recursos constitucionales y legales que pueden ser utilizados para su protección (Uprimny, 2006, p.10).

Otro concepto es el elaborado por la sociología, el cual parte de que estos derechos no son objetos o posesiones, no son ni están en la carne, el hueso y el alma de las personas, sino que son relaciones sociales en diversos ámbitos (no solamente jurídicas) entre las personas y entre personas e instituciones, de las cuales se derivan las exigencias para que el comportamiento sea ajustado de determinada manera, esto es, son relaciones de convivencia básica. Su objeto es limitar el "poder" de unas personas e instituciones sobre otras, y sustraer ciertos ámbitos de la disposición y capacidad de decisión de los centros de poder públicos o privados, los cuales pueden afectarlos por acción o por omisión (Cfr. Fariñas, 1998, 1998a).

También se ha propuesto un concepto integral de estos derechos como categoría 
del pensamiento o del mundo de las ideas, y también como categoría material. Lo que se busca es integrar la naturaleza metafísica e ideal de su concepción con la materialidad y la realidad social de estos derechos, por esto se les presenta como derechos jurídicos subjetivos, los cuales protegen tanto la concepción o idea de la persona (dimensión metafísica) como la materialidad reflejada de las necesidades básicas de la existencia social moderna (dimensión material) ( $\mathrm{Cfr}$. Bernal, 2010, Arango, 2005).

Finalmente, es necesario presentar el concepto que se deriva de la sociología de los sistemas sociales, y que es definido desde una perspectiva sociológica, alejada del paradigma filosófico idealista. En esta propuesta, los derechos humanos no son algo que está en el ser humano (mente/ cuerpo) o que es construido como una idea por la razón y la interacción entre seres humanos y tampoco son una mera categoría normativa internacional (tratado) o derecho interno constitucional y legal.

Por esta razón, los derechos humanos se conciben y definen como una categoría sociológica comunicativa, que está en permanente construcción social y no es absoluta. Es decir, en cada decisión, que es comunicada, dichos derechos pueden ser negados o afirmados y, por tanto, siempre responderán a esa naturaleza contingente. De igual manera, esta teoría considera que quienes toman decisiones y comunican dichas negaciones $o$ afirmaciones de derechos humanos y fundamentales no son las personas individuales, sino que también pueden ser los sistemas sociales como las universidades, las clínicas u hospitales, las empresas, la fiscalía, los tribunales, juzgados, entre otros (Luhmann,1993, p.172; Teubner, 2005, p.551).

\section{LA FUNDAMENTACIÓN DE LOS DERECHOS HUMANOS}

Ahora bien, las diversas fundamentaciones están en la permanente búsqueda de las razones sobre por qué determinados derechos son derechos humanos y fundamentales y porqué deben ser reconocidos, protegidos y construidos, de manera especial, en el orden jurídico y social.

En este escenario es donde se han librado los más intensos debates del orden teológico, filosófico, sociológico, económico, antropológico y jurídico, y donde se han buscado las razones y fundamentos "éticos, morales, políticos, jurídicos" más profundos para la construcción, aceptación y protección de estos derechos (Alexy, 2000, p.28) ${ }^{1}$.

En primer lugar, la corriente filosófica humanista, la cual tiene como máxima central que sólo desde el enfoque iusnatural tiene sentido plantear el problema de la fundamentación de estos derechos. La razón básica es que los derechos naturales pueden ser conocidos, justificados y protegidos racionalmente $\mathrm{y}$, en esa medida, en toda relación social y en todo sistema social que sea creado y esté compuesto por los hombres como el derecho, la política y la empresa se pueden y deben reconocer tales derechos al tomar y comunicar decisiones para su protección o decisiones que los pueden afectar (Cfr. Hart, 1973. Pérez, 1983).

Una segunda gran corriente filosóficojurídica de la fundamentación se puede agrupar bajo el constructivismo ético que, sin abandonar los valores y principios morales, considera que estos son la base para construir los derechos en los sistemas político y jurídico, pero también, por esa vía, en todo el orden social-práctico.

Estos valores son presentados en diferentes escenarios de discusión prácticos como el derecho, la legislación, la ciencia, la IA, la sociedad digital, las políticas y la administración pública, las redes sociales, las nuevas tecnologías, la globalización económica, etc. (Crf. Rawls (1996 y 1979), Nino (1988 y 1989), Alexy (1998), Habermas (1994) y Kaufmann (1998)).

1. Aunque Alexy considera que los derechos humanos deben ser normas internacionales de derecho internacional público con un contenido concreto (protección y satisfacción de necesidades e intereses fundamentales para el ser humano), él considera que la construcción y la aceptación de estos derechos es un asunto discursivo que involucra la moral y a toda la humanidad (Pérez, 1983, p. 13). 
De esta forma, los derechos humanos se construyen y pueden ser aceptados sobre el discurso y la argumentación presentada en diferentes escenarios sociales, políticos, jurídicos, económicos, internacionales y científicos, en los que se requiere dicha construcción y fundamentación. En esta perspectiva prima el aspecto discursivo, argumentativo y moral, el cual involucra a toda la humanidad como el fundamento esencial para la construcción de estos derechos en los procesos políticos, normativos, económicos, así como en la ciencia y en las nuevas tecnologías.

Una tercera fórmula de fundamentación es presentada por la sociología de los sistemas sociales que, como se ha visto, considera que los derechos humanos no son mente/cuerpo, sino comunicación sobre derechos/no derechos.

En este sentido, el fundamento o la razón de ser de los derechos humanos está en la función social que cumplen, que ya no es solamente la protección directa de los seres humanos, sino que sirve para proteger el orden social o los sistemas de comunicación en la que están contenidos una multiplicidad de los ámbitos de la personalidad como la democracia, la separación de poderes, la propiedad privada, la salud, la autonomía educativa, las funciones de control de las superintendencias, entre otras.

Esta perspectiva indica que antes que proteger directamente derechos como la salud de la persona, lo que se debe proteger y fortalecer es la existencia y las funciones que cumplen las organizaciones e instituciones que hacen parte del sistema de la salud, pues es allí donde se elaboran y comunican las decisiones (resoluciones, directivas, políticas) en las que se generan las afirmaciones o amenazas y vulneraciones a los derechos humanos. (Cfr. Luhmann (2010) y Nassehi (2005)).

En el caso de internet, por ejemplo, como derecho humano y como derecho fundamental, los expertos de las Naciones Unidas han indicado que este medio es un derecho humano porque permite incluir a la persona en la dimensión comunicativa digital, es decir, garantiza su participación en la comunicación global digital y en el intercambio, recepción y difusión de información.

Otra razón que se puede agregar es que este medio tecnológico trae o propicia el desarrollo y el progreso, en la medida en que activa las relaciones entre comunidades y grupos con las instituciones públicas. Sin embargo, el argumento central de la fundamentación es que este medio es una herramienta fundamental para el ejercicio de la libertad de expresión y la participación ciudadana y, por eso, debe ser garantizado y no debe ser objeto de limitaciones arbitrarias en su uso y contenido por parte de los gobiernos.

En Colombia, por ejemplo, se han propuesto varios proyectos de ley y actos legislativos para consagrarlo como derecho fundamental, entre ellos, uno orientado a reformar el artículo 20 de la Constitución en el cual se establecía el acceso a la banda ancha.

\section{LA MATERIALIZACIÓN DE LOS DERECHOS HUMANOS}

Los análisis pioneros en el estudio de la materialización de los derechos humanos la asocian a la positivización de los principios y valores como normas universales (tratados) y también como normas internas de derechos fundamentales, sociales y colectivos. Según Alexy, la fórmula más indicada para la realización de los derechos humanos es mediante la universalización del modelo político y jurídico del Estado social democrático y de derecho (Alexy, 2000, p.31).

En la actualidad, la materialización de los derechos humanos es uno de los aspectos más problemáticos y complejos. La razón es que hoy está claro que para la realización de estos derechos no basta la positivización de un derecho como derecho humano, en el nivel universal o regional mediante tratados, como tampoco su consagración a nivel estatal como derecho fundamental, social 
o colectivo. En ese mismo sentido, tampoco son suficientes las herramientas e instancias de protección jurídica, las cuales caracterizan a estos derechos en el plano estatal como internacional.

Es por esto que uno de los campos de análisis que más se ha enriquecido en las últimas décadas es: cómo se ha de hacer efectiva la materialización y protección efectiva de estos derechos en la realidad institucional y social universal como estatal.

En este sentido, el punto de partida de los diferentes análisis es que buscan ser consecuentes con las aceleradas transformaciones políticas, administrativas, jurídicas, económicas, tecnológicas, culturales que viene experimentando la sociedad estatal y global (Cfr. Uprimny y Rodríguez, 2007).

De igual forma se verá, por un lado, que con la emergencia de la sociedad, a nivel mundial o global, se están generando nuevos problemas, instituciones, derechos, formas de vulneración, movimientos y organizaciones sociales, fórmulas jurídicas, políticas y económicas, mediante las cuales se busca gestionar y encarar los problemas que afectan a la comunidad global, entre ellos las violaciones sistemáticas a los derechos humanos y fundamentales (gobernanza global).

Por otro lado, se verá también y en el nivel estatal, la descentralización de la sociedad, la cual ha provocado que la materialización de los derechos fundamentales, sociales y colectivos no se quede reducida a norma jurídica constitucional, legal o acto administrativo. Debido a lo anterior, se está consolidando un marco analítico, el cual considera que en el análisis de la materialización de los derechos humanos se deben tener en cuenta las siguientes instituciones:

\section{LA MATERIALIZACIÓN GLOBAL DE LOS DERECHOS HUMANOS}

En el sistema universal de derechos humanos, la materialización se realiza mediante la positivización, en la cual se afirma el carácter normativo de estos derechos y se produce la vinculación política y jurídica de los estados frente a su respeto. Este proceso inicia con la conformación de la sociedad de Estados y la firma de la Carta de las Naciones Unidas (1945), la Declaración Universal de Derechos Humanos (1948) y, en el caso de Colombia, con la firma y ratificación de los tratados internacionales, incorporados y aplicados en el ordenamiento interno mediante el bloque de constitucionalidad.

Lo anterior porque estos tratados los establecen órganos muy importantes, encargados de velar por el cumplimiento de los deberes y las responsabilidades asumidas por los Estados, así como por la eventual sanción por su incumplimiento (convencionales) (Uprimny, 2008).

Cabe agregar que en el sistema universal también se han desarrollado las normas del Derecho Internacional Humanitario (DIH) o las normas de la guerra, las cuales se deben aplicar, tanto en conflictos armados internacionales como en conflictos internos, con el fin de proteger las personas y los bienes y limitar el uso de armas y métodos de guerra.

En el ordenamiento interno, estas normas se han desarrollado principalmente en cuatro órdenes: la Constitución ${ }^{2}$, el Código Penal $^{3}$, el Código Penal Militar ${ }^{4}$ y el Código Disciplinario Unico ${ }^{5}$. Así mismo, existe un conjunto de directrices y directivas internas, las que establecen órganos y procedimientos internos de la Fuerza Pública para aplicar y

2. Al respecto se deben consultar los artículos 26219.

3. Esta afirmación se complementa con la siguiente disposición: Ley 599 de 2000. Libro II, Título II, capítulo único, tipifica los "delitos contra personas y bienes protegidos por el Derecho Internacional Humanitario" los artículos 135 a 164.

4. Esta afirmación se complementa con la siguiente disposición: La Ley 522/99. Art. 3 establece "En ningún caso podrán considerarse como relacionados con el servicio los delitos de tortura, el genocidio y la desaparición forzada, contenidas en los convenios internacionales y además en la ley 734 de 2002.

5. Esta afirmación incluye un capítulo de las faltas gravísimas que se sancionan con destitución del cargo e inhabilidad general, una serie de conductas que constituyen violaciones al DIH. 
cumplir con las normas del DIH, como por ejemplo en el desarrollo del combate contra las organizaciones criminales (GAO) ${ }^{6}$.

Finalmente, el sistema universal cierra con el Derecho Penal Internacional, el cual crea la primera institución permanente, encargada de investigar y juzgar individuos que cometan crímenes internacionales lesa humanidad, genocidio, agresión y crímenes de guerra). Dicha jurisdicción se podrá activar cuando los sistemas nacionales se muestren incapaces o no tengan la voluntad de investigar y juzgar a los responsables de estas violaciones establecidas en el Estatuto de Roma.

A nivel estatal, han sido consagradas normas por esos graves delitos de trascendencia internacional en la Ley 599/00 como el Genocidio (art. 100), los crímenes de guerra (131-165) y los delitos de lesa humanidad, cuando los delitos ordinarios, consagrados en el ordenamiento jurídico penal colombiano sean cometidos de manera sistemática contra la población civil en tiempos de paz o guerra (Ambos, 2000, p.141; Ramelli, 2011, p.469)7.

\section{LA MATERIALIZACIÓN REGIONAL (INTERAMERICANA)}

Sobre este aspecto se puede afirmar que el Sistema Interamericano de Derechos Humanos tiene origen con la Declaración Americana de Deberes y Derechos del Hombre de 1948, donde se establece el catálogo de derechos, los cuales deben ser respetados por los Estados. Seguidamente, en 1969 se aprobó la Convención Americana de Derechos Humanos, que entró en vigencia en 1978, donde se establecieron las obligaciones y los derechos que los Estados debían garantizar $\mathrm{y}$, de forma adicional, se encuentra que se han firmado tratados interamericanos en varias materias ${ }^{8}$.

6. Aquí se hace referencia al origen del concepto y sobre la consagración en el derecho internacional de este delito ver Vicepresidencia, 2010, p. 27.

7. Sobre el tema del Derecho Penal Internacional, este se debe complementar con Ambos (2000, p.141) y Ramelli (2011, pp.469-470).

8. Existen además otros sistemas regionales son: 1 . El sistema africano de derechos humanos inicia con
Las principales instituciones de este sistema son, por una parte, la Corte Interamericana de Derechos Humanos, órgano judicial que interpreta y aplica la Convención IDH, decide o tramita los casos que se presentan contra los Estados y define las responsabilidades internacionales del Estado por las violaciones demandadas.

Por otra parte, se encuentra la Comisión Interamericana de Derechos Humanos Comisión IDH-, la cual tiene, entre sus funciones, elaborar informes sobre la situación de los derechos humanos en los Estados americanos y, además analizar la situación y proferir recomendaciones, dar trámite a los casos individuales o colectivos de denuncias contra los Estados y analizar la admisibilidad de la denuncia, así como admitir que los hechos denunciados pueden constituir una violación a los derechos humanos, en cuyo caso propondrá una solución amistosa y emitirá recomendaciones o enviará el caso a la corte IDH, que hoy es la regla general que aplica la Comisión.

Finalmente, la comisión IDH tiene una función muy importante porque puede tomar medidas cautelares para proteger a las personas o grupos ante el riesgo inminente para la vida y la integridad ${ }^{9}$.

Ahora bien, dentro del proceso de institucionalización de los derechos humanos, a nivel interamericano, se ha registrado una evolución muy importante, la cual implica una mayor articulación entre el nivel interamericano y el estatal. Aquí la jurisprudencia interamericana ha construido el control de convencionalidad como una figura que debe ser aplicada por los jueces de nivel estatal, para realizar un control y ajuste

la Carta del 81, entró en vigencia en 1986 y la corte africana DDHH en 2006; 2. el sistema europeo inicia con el convenio europeo de DDHH de 1950 y la carta social europea de 1961 (Botero y Guzmán, 2007, p.22).

9. Este aspecto se complementa con Uprimny y Parra, 2006, p.116. En donde se explica: Estos autores nos recuerdan algo muy importante como es: "Las diferentes etapas del proceso ante estas instancias son el examen preliminar de la demanda donde se examinan las cuestiones de admisibilidad; la contestación de la demanda y presentación excepciones preliminares por parte del Estado; audiencias sobre excepciones preliminares, sobre el fondo y eventuales reparaciones". 
de las normas y prácticas nacionales frente a la Convención Americana de derechos humanos.

Es decir que, por ejemplo, los jueces en Colombia no deben únicamente aplicar las normas nacionales, la Constitución y la jurisprudencia, sino que deben realizar, tanto el control de constitucionalidad como de convencionalidad para verificar que la aplicación de normas internas no merma las disposiciones de la Convención; de igual forma, porque deben aplicar la interpretación o la jurisprudencia trazada por los organismos interamericanos.

Los elementos que componen el control de convencionalidad son: 1 . De oficio o por solicitud para verificar la compatibilidad de las normas y prácticas internas con la Convención y otros tratados interamericanos; 2. Las obligaciones de los jueces, de todo órgano vinculado a la administración de justicia y pública en todos los niveles y según el ámbito de su competencia; 3. Por otro lado, para determinar la compatibilidad con la Convención se deben tener en cuenta todos tratados de Derechos humanos interamericanos y la jurisprudencia de la Corte IDH; 4. Finalmente, la ejecución de este control puede implicar la no aplicación o la supresión de normas contrarias a la Convención (CIDH, pp.1-25).

\section{LA MATERIALIZACIÓN DE LOS DERECHOS FUNDAMENTALES SOCIALES Y COLECTIVOS} La fórmula básica para la
institucionalización de los derechos humanos indica que estos se deben realizar, en primer lugar, como derecho estatal, es decir, como derechos fundamentales, sociales y colectivos. La doctrina considera, en este sentido, que la fórmula institucional más idónea para que los Estados cumplan con las obligaciones contraídas internacionalmente, así como para materializar los derechos humanos como derechos fundamentales, mediante la consolidación del Estado Social de Derecho (Alexy, 2000, p.31).
Sin embargo, en la doctrina poco se habla de los procesos de desinstitucionalización de estos derechos o de los procesos regresivos en la materialización de los derechos sociales y el desmonte del Estado de derecho en varios países de la región. Se trata entonces de un fenómeno de desinstitucionalización progresiva, la cual comienza con la toma del poder político, la anulación de la división de poderes y controles al ejecutivo y el recorte de la democracia y de la propiedad privada.

Todo ello llevará al deficiente manejo y corrupción en los derechos fundamentales y sociales como educación, salud, vivienda $\mathrm{y}$, en general, al recorte de derechos $\mathrm{y}$ garantías básicas que afectan los derechos constitucionales ${ }^{10}$.

La teoría política, por otro lado, considera que en muchos países de la región latinoamericana se presenta una realidad social contradictoria, donde los derechos fundamentales básicos como la seguridad, la propiedad, la vida, la libertad, la dignidad, el debido proceso y el acceso a la justicia, no son garantizados y se presentan defectos básicos en la consolidación del Estado social de derecho democrático.

Incluso, se considera que algunos estados de derecho, están amenazados por tendencias regresivas hacia la desintegración institucional y la premodernidad o el Estado de naturaleza, con las graves consecuencias que esto tiene para la institucionalización de los derechos humanos y la consolidación

10. Sobre esto ver Bernal (2007, pp.225 y ss.), quien considera que el hiper presidencialismo en América Latina, y el déficit de control parlamentario trajo, como consecuencia, un control del poder por parte de los tribunales constitucionales, necesario para fortalecer el respeto de los derechos fundamentales por parte del Estado. Principalmente, en la toma de decisiones frente a las modernas amenazas contra los bienes del Estado, especialmente la seguridad, las crisis económicas, entre otras. Sin embargo, como lo muestra la experiencia Latinoamericana, los sistemas constitucionales como sistemas centrales y jerárquicos también son una vía allanada para la desdiferenciación de la sociedad pues la toma de esa institución implicaría facilitar reformas constitucionales que puedan traer la violación sistemática de los derechos humanos y fundamentales o fenómenos contrarios a la democracia como la reelección indefinida y la desdiferenciación económica de la sociedad (Ver caso Venezuela). 
de la democracia (Di John, 2010, pp.46-86; Gonzáles y Rettberg, 2010, pp.131-137) ${ }^{11}$.

En Colombia, recientemente con la firma del Acuerdo Final, se crearon una serie de instituciones dirigidas a producir cambios $\mathrm{y}$ ajustes institucionales para realizar la inclusión social de las regiones azotadas por el conflicto, el abandono del Estado, la violencia, las organizaciones y las economías criminales, en conjunto, además de consolidar el Estado social de derecho en estos territorios como fundamento básico para la construcción de la convivencia y la paz.

Entre otros se pueden mencionar los Programas de Desarrollo con Enfoque Territorial (PDET), (Decreto 893/17), la Unidad Especial de Investigación para el desmantelamiento de las organizaciones y conductas criminales y sus redes de apoyo (Decreto 898/17), el Sistema Integral de Seguridad para el Ejercicio de la política (Decreto 895/17), el Sistema de prevención y alerta para la reacción rápida (Decreto 2124/18); el Plan Horus o la estrategia para activar la presencia y la efectividad de la Fuerza Pública en los territorios en los que hacía presencia las FARC, la ruta de Protección individual (Decreto 1066/15), la ruta de protección colectiva (Decreto 2078 de 2017), la ruta de Protección de comunidades $\mathrm{y}$ organizaciones en territorio (decreto 660/18), y el Programa Nacional Integral de Sustitución de Cultivos de Uso Ilícito. PNIS. (Acto legislativo 01/16 y Decreto 672/15).

De igual forma, en Colombia se ha evolucionado hacia la institucionalización de un derecho fundamental como la salud, establecido en los artículos 49 y 50 de la Constitución. A pesar de esto, ha quedado claro que, así como no basta la mera Declaración Universal de un derecho, tampoco basta su consagración estatal como derecho fundamental mediante jurisprudencia o Ley Estatutaria (1751/15).

11. Debido a muchas falencias del Estado colombiano, sobre todo en materia de la institucionalización de los derechos fundamentales, aunque no es fallido apenas está en proceso de construcción como Estado de derecho.
Por el contrario, la evidencia muestra que persisten las deficiencias en la institucionalización de este derecho como derecho fundamental, lo cual se refleja en que no ha disminuido el número de tutelas por las amenazas y negaciones de este derecho y servicio público por parte de los sistemas de organización que componen el sistema de salud (público, privado o mixto) ${ }^{12}$.

\section{LA MATERIALIZACIÓN GLOBAL MEDIANTE EL SOFT LAW}

Uno de los rasgos especiales de las nuevas formas jurídicas y las instituciones universales que están en emergencia, para hacer efectivos los derechos humanos, es que son construidas bajo lo que ha sido denominado como el Soft law. Este tipo de derecho universal y las instituciones que emanan de él, se desarrolla en ámbitos de poder decisivos para los derechos humanos como son las empresas multinacionales, los servicios globales de comunicación, la sociedad virtual, la globalización económica, los acuerdos comerciales, el medio ambiente global, las leyes de construcción internacional, la investigación científica, entre otros (Cfr. Ángel (2008, pp. 15-16) y Castro (2014, pp.1-115).

Se trata así de un conjunto de nuevos principios, normas e instituciones globales $\mathrm{y}$ estatales que pueden ser denominados como Sotf law, y que son presentados como Responsabilidad Social Empresarial (RSE), ethic business o debida diligencia.

12. En este sentido se debe complementar la información con la Defensoría de Pueblo (2013, p. 247). Este estudio concluye que desde la sentencia T-760/08 no ha disminuido el número de tutelas ni la violación o negación sistemática de este derecho fundamental por parte de las entidades prestadoras de este servicio. Por su parte, Arango (2007, pp. 89 y ss.) presenta la evolución del derecho a la salud y la seguridad social, desde la contradicción entre la realización del Estado social bajo la dirección, coordinación y control del Estado, y la prestación del servicio por particulares bajo la lógica privada. Todo lo cual supone un acuerdo de cooperación público privado que ha sido objeto de tratamiento sistemático por la jurisprudencia de la corte constitucional. Ver también Parra (2003) y Procuraduría General de la Nación (2008, pp. 196 y ss.). Este último estudio se centra en que los ajustes en el sistema de la Salud se deben generar externamente desde los meros sistemas públicos de control de la superintendencia y principalmente desde el sistema constitucional y legal. 
Este orden se basa en los principios de la autonomía, la autorregulación y la autoorganización de sectores y actores, y la comprensión de normas como los Principios Rectores sobre las Empresas y los Derechos Humanos, las Directrices de la OCDE para las Empresas Multinacionales y las Guías de Responsabilidad Social Empresarial ISO 26.000 .

También comprende los códigos de conducta propios que se dan a sí mismos actores como las empresas multinacionales, en los que se incluyen apartados sobre el respeto de los derechos humanos. Además, en el soft law, también se generan instituciones articuladas a nivel estatal, como los Puntos Nacionales de Contacto (PNC) de la OCDE del Ministerio de Comercio, los cuales están establecidos para tratar los asuntos y conflictos entre el EMN y las comunidades, incluidos los derechos humanos.

Sin embargo, se critica que estos marcos de conducta son generados autónomamente por los mismos regulados, son de libre adhesión, no se imponen verdaderas responsabilidades jurídicas y sanciones por el incumplimiento, ni verdaderos deberes de prevención de violaciones de derechos humanos, ni la obligación de implementar programas de prevención del riesgo de violaciones de derechos humanos efectivos y tampoco existen autoridades u órganos de supervisión, control y sanción (Cfr. Martín (2008, pp.149 y ss.), Ángel (2008, pp.15-16) y Castro (2014, pp.1-115)).

\section{LA MATERIALIZACIÓN MEDIANTE POLÍTICAS PÚBLICAS ESTATALES}

Otro aspecto muy importante para la institucionalización y materialización de los derechos fundamentales sociales $\mathrm{y}$ colectivos, es que se vienen incorporando análisis de derechos fundamentales sociales y colectivos basados en la metodología de las políticas públicas. Esto es, se utiliza el ciclo de política pública, el cual consta de los siguientes pasos: la construcción de los problemas sociales, el diseño, la implementación y la evaluación del conjunto de acciones, programas y medidas para solucionar dicho problema.

Al respecto, es preciso aclarar que las políticas públicas no solamente están asociadas a los derechos sociales, en cuanto prestaciones progresivas a cargo del Estado o de instituciones privadas que requieren de políticas públicas dirigidas a la financiación, la administración y la gestión de recursos públicos y privados en áreas como la educación, la vivienda, entre otros.

Este análisis también es utilizado y está asociado a los pronunciamientos de la Corte Constitucional en ámbitos muy complejos, en los que ha sido muy problemático materializar los derechos fundamentales como la dignidad de los presos y el desplazamiento forzado. Incluso, en estos escenarios se ha dicho que la Corte Constitucional ha desbordado su competencia porque llega a plantear y trazar políticas públicas que tiene que implementar el gobierno ante los estados de cosas inconstitucionales.

Teórica y metodológicamente esta perspectiva analítica es más efectiva para analizar la materialización de los derechos fundamentales, sociales y colectivos, toda vez que permite superar el mero análisis normativo constitucional o legal, y los actos administrativos mediante los cuales se toman decisiones orientadas a materializar esos derechos.

Esta metodología permite construir los problemas concretos institucionales para los derechos fundamentales, sociales y colectivos, luego plantea el diseño, la implementación y la evaluación del conjunto de medidas, acciones programas, los tiempos, los ejecutores y los responsables de las mismas. Además de ello, permite identificar los problemas y las soluciones, desde una perspectiva integral, de las causas sociales que generan las afectaciones a estos derechos o la negación de estos derechos y de las soluciones que plantean las instituciones públicas y privadas encargadas de gestionarlos. 
En este punto se reitera que una de las grandes ventajas de esta metodología es que ha permitido sacar los análisis de los derechos fundamentales, sociales $y$ colectivos de la mera esfera constitucional y legal para conectarlos a la toma de decisiones concretas de las organizaciones públicas y privadas, dirigidas a materializarlos.

Además, las normas y los actos administrativos solamente son una parte de la implementación de las políticas públicas y no su efectiva materialización. De esta forma, el enfoque de políticas públicas permite contemplar la construcción de los problemas jurídicos de derechos humanos, el diseño, implementación y evaluación de las acciones, planes y medidas concretas de las instituciones para prevenir las vulneraciones y respetar y materializar estos derechos mediante políticas públicas integrales.

\section{LA MATERIALIZACIÓN DE LOS DERECHOS HUMANOS Y FUNDAMENTALES Y LA ACCIÓN DE LAS ORGANIZACIONES Y REDES DE ORGANIZACIONES DEFENSORAS DE DERECHOS HUMANOS}

Tal como se transforman los actores institucionales de los derechos humanos, también se transforman las organizaciones que luchan por su defensa, reconocimiento y la materialización.

$\mathrm{Al}$ respecto y en primer lugar se puede decir que resulta necesario que estas organizaciones generen órganos internos especializados en diversas temáticas y con capacidades y competencias de observación y análisis de fenómenos globales de derechos humanos que, debido a su complejidad, requieren de esta experticia.

Como se dijo previamente, ante áreas complejas como la prestación de servicios públicos, el agua, el internet, las empresas multinacionales, la investigación científica, la economía global, el medio ambiente, la corrupción, la alimentación, por ejemplo, se requiere de nuevas competencias, fórmulas y equipos interdisciplinarios de estudio.
En segundo lugar, estas organizaciones están adecuando las metodologías de investigación a esas realidades, por ejemplo, mediante prácticas de investigación-acción, y otras fórmulas de interacción entre ciencia, instituciones y poblaciones. Esto es, que ellas participan en la esfera pública o en alianza con movimientos sociales y buscan medios para incidir en el desarrollo de políticas públicas o en la construcción de acciones y programas para solucionar los problemas de derechos humanos en casos concretos (Rodríguez, 2013).

En tercer lugar, otra de las áreas que viene consolidándose es el litigio estratégico de derechos humanos, fundamentales, sociales y colectivos ante jueces y altos tribunales de nivel local, regional y universal.

Por ejemplo, en Colombia, la organización Dejusticia, la cual ha intervenido en diversos asuntos como la demanda de revisión de una tutela contra la Superintendencia de Industria y Comercio, por no actuar frente a la publicidad engañosa de las empresas que han generado riesgos en los derechos de los menores. De igual manera, ha actuado e intervenido mediante ayuda o amicus curiae en otros procesos internos e internacionales por invitación de los demandantes o de las cortes $^{13}$.

Así mismo, una de las formas de organización que se requieren para actuar en la sociedad moderna es interactuar en redes junto con otras organizaciones o en colaboración y cooperación para generar conocimiento, el litigio y la investigación, con el fin de alcanzar la dimensión global que alcanzan los problemas de derechos humanos ${ }^{14}$.

\section{LA MATERIALIZACIÓN DE LOS DERECHOS Y EL ORDEN ECONÓMICO GLOBAL}

\footnotetext{
13. Información adicional se puede consultar en el siguiente enlace: Ver http://xurl.es/hdrf2

14. De forma complementaria se puede consultar: Dejusticia. Taller global de investigación acción. ¿Por qué es importante la colaboración entre organizaciones del Sur Global? Disponible en: http://xurl.es/aawqu.
} 
A pesar de las declaraciones y los tratados y principios universales de derechos humanos firmados por los Estados, recientes estudios que se señalarán más adelante, indican que uno de los principales hechos que va en contravía de la materialización de estos derechos son los factores que impiden la realización de los derechos sociales en los Estados pobres, debido a que persiste un orden económico-global y de instituciones injustas.

Estas formas de intercambio y producción económica global benefician los intereses económicos y comerciales de los Estados desarrollados y de los agentes o empresas multinacionales (EMN), agravando los problemas y causas sociales que generan la violencia, pobreza y la exclusión social.

Sobre esto, Pogge considera que en el orden mundial predomina un sistema económico orientado por las reglas del mercado, el cual es dominado por las instituciones del sistema económico liberal clásico, en donde se trazan directrices y políticas como el Banco Mundial, el Fondo Monetario Internacional, los principios del Consenso de Washington, la OCDE, entre otras.

A su vez, el impacto de este orden, lo padecen no solamente los ciudadanos de los Estados menos desarrollados, sino que también afecta a los ciudadanos pobres de los Estados desarrollados que han visto el desmonte de algunos logros en materia de derechos sociales como la educación, la salud, la seguridad social, el trabajo, entre otros.

Entonces, existe una gran paradoja global para los Estados, porque de una parte se establecen tratados de derechos humanos que exigen obligaciones en esas materias, mientras que, de otra parte, las instituciones globales económicas le exigen a los Estados el desmonte de políticas sociales, de subsidios, el recorte del gasto social para generar la estabilidad macroeconómica y fiscal, la reducción del gasto, el control de la inflación, entre otros (Pogge, 2008, p.29).
Evidencia de lo anterior es el acrecentamiento de los problemas entre los negocios de las empresas multinacionales versus los derechos de los ciudadanos de Estados pobres. Al respecto y en la actualidad, se afirma que son numerosos los litigios que se están llevando ante la justicia internacional competente en estos asuntos (arbitraje de la Cámara de Comercio Internacional, la CNUDMI).

Por ejemplo, una demanda en Latinoamérica versa sobre el "derecho humano al Agua" (caso Tunari S.A vs Bolivia) en la que la empresa española demandó al gobierno Boliviano por daños a la inversión $\mathrm{y}$ al lucro cesante, por una suma de entre 25 y 100 millones de dólares ante el CIADI, alegando que se ve afectada con las políticas estatales, las cuales han llevado a la nacionalización de este servicio ${ }^{15}$.

Frente a esta situación, se vienen planteando análisis que proponen la reconstrucción de una justicia social universal, esto es, la generación de nuevos principios y la corrección de las instituciones y normas que generan la pobreza, la inequidad y las desigualdades.

Por su parte, Stiglitz ha sido abanderado del "neoinstitucionalismo económico global", el cual propone que el sistema económico global debe auto reformar sus principios e instituciones trazadas desde el consenso

15. De acuerdo con la afirmación se puede definir de la siguiente manera: "El CIADI es una institución de arreglo de diferencias independiente, apolítica y eficaz. El hecho de que se encuentre a disposición de inversionistas y Estados ayuda a promover la inversión internacional fomentando la confianza en el proceso de resolución de controversias. También está disponible en el caso de controversias entre Estados en virtud de tratados de inversión y tratados de libre comercio, al igual que como registro administrativo. El CIADI prevé el arreglo de diferencias mediante conciliación, arbitraje o comprobación de hechos" Lo anterior se puede consultar en: https://bit.ly/2DlK5na. Además, otra demanda presentada ante los tribunales de arbitramento es la de Gas Natural Fenosa Contra Colombia ante el Tribunal de la Comisión de las Naciones Unidas para el Derecho Mercantil Internacional (Cnudmi o Uncitral en inglés) para reclamar a Colombia más 1000 millones de euros por la liquidación de Electricaribe. Por una parte, la empresa alega que la intervención de la empresa es una expropiación sin indemnización que le causó daños, mientras que el gobierno alega que la decisión buscaba garantizar a prestación del servicio de energía a los habitantes de la costa atlántica colombiana. 
de Washington (Stiglitz, 2008, pp.58-60). Además, otros estudios argumentan que esas reformas en la lucha contra la pobreza y la justicia social global deben ser producidas en clave de derechos humanos en los niveles universal, regional y estatal (Ramírez, 2009; Cortés, 2007, p.137).

\section{LA MATERIALIZACIÓN DE LOS DERECHOS HUMANOS MEDIANTE LA EXIGENCIA DE PROGRAMAS DE PREVENCIÓN Y GESTIÓN DEL RIESGO, DE VIOLACIONES DE DERECHOS HUMANOS Y FUNDAMENTALES EN LAS ORGANIZACIONES PÚBLICAS Y PRIVADAS}

Ahora bien, una de las principales fórmulas que se está estudiando y desarrollando en la materialización de los derechos humanos, en las organizaciones públicas y privadas, es que sean implementados programas internos de cumplimiento normativo, prevención y gestión del riesgo de factores asociados a las vulneraciones de derechos humanos y fundamentales en cada decisión concreta que puede afectarlos.

Por eso, instituciones públicas y privadas asumen deberes de implementar programas y órganos internos encargados de prevenir y gestionar el riesgo de eventuales lesiones a los derechos fundamentales que se pueden derivar de sus actividades y decisiones.

La nueva lógica está enfocada en la prevención del riesgo e indica que, en materia de derechos humanos, las organizaciones públicas y privadas deben realizar mayores esfuerzos para implementar sistemas proactivos o predictivos del riesgo. Es decir, tienen deberes de desarrollar programas e instituciones internas con la capacidad de gestionar y analizar información relevante para detectar, identificar, analizar e implementar medidas para el control, gestión y neutralización de los riesgos para los derechos fundamentales que se pueden derivar de sus actividades (Comisión
Intersectorial de Alertas Tempranas, 2012, p.24 y ss.; Presidencia de la República, 2014, p.51).

Por un lado, frente a las organizaciones privadas se están dictando normas administrativas $y$ penales que no se enfocan en la mera sanción, sino en la prevención de los riesgos por parte de los mismos regulados. Para ello se establecen causales de atenuación o exoneración de la responsabilidad en áreas como el medio ambiente, la corrupción privada trasnacional, la actividad financiera, entre otros.

Como parte de esta tarea, han de ajustar el gobierno, la cultura corporativa y los órganos internos de gobierno y control (auditorias, programas de cumplimiento) con el fin de que se implementen sistemas eficaces y órganos de control responsables del cumplimiento del derecho y la prevención de dichos riesgos. Por otro lado, las instituciones públicas ejercen la supervisión, el control y la sanción por los defectos de la autorregulación o por la no implementación de sistemas eficientes de prevención y gestión de estos riesgos.

En el caso de los ministerios y las superintendencias, en áreas como el medio ambiente o la corrupción en la administración de las finanzas públicas, se están implementando normas administrativas en las que más que sancionar se busca que las organizaciones públicas y privadas adopten estos sistemas de cumplimiento y prevención.

En conjunto, se trata de la tendencia evolutiva encaminada a la gradual consolidación de los principios de la autonomía, la auto organización y la autorregulación de las empresas y las organizaciones públicas para darse autónomamente valores, principios, normas éticas y técnicas, cuyo fin primordial no es otro que la prevención y gestión de los riesgos, que se pueden derivar de su actividad, para los derechos humanos $\mathrm{y}$ fundamentales (Pérez, Botero (2012). 
Esto es, que se vienen desarrollando deberes concretos en muchas áreas como la corrupción, las malas prácticas en la administración de recursos (contables y financieras), las políticas y las directrices del gobierno corporativo y las organizacionales contrarias a los derechos fundamentales, el cumplimiento de las normas en las que se establecen los estándares de riesgos para los derechos fundamentales sociales y colectivos (Gómez y Corominas, 2017, pp.169-191; Manual práctico de compliance, 2017, p.104; Aranzadi, 2017, pp.26 y ss.).

\section{LAS RESPONSABILIDADES EN MATERIA DE DERECHOS HUMANOS}

Los análisis sobre las responsabilidades por el respeto/no respeto de los derechos humanos y fundamentales, también buscan ser consecuentes con los cambios y la evolución de la estructura institucional global y estatal, que han generado nuevas formas e instituciones descentralizadas y no jerárquicas para establecer responsabilidades.

\subsection{LA RESPONSABILIDAD CIVIL}

La responsabilidad civil universal ha sido poco discutida, además tampoco se han hecho propuestas para la creación de una jurisdicción civil universal a la que las víctimas puedan recurrir para que sean reparados los daños y, así mismo, la implementación y pertinencia de este tipo de reparación no goza, por ahora, de consenso universal (Díaz, 2002, pp.872 y ss.) ${ }^{16}$.

En este tema existen estudios que la contemplan como la solución más idónea para demandar y litigar cuando ocurren

16. La posibilidad de que los Estados ejerzan justicia universal en materia penal, se inicia cuando los tribunales de los países aliados ejercen, en nombre de la comunidad internacional, justicia por los graves delitos cometidos durante la Segunda Guerra. En la actualidad se reconoce que los estados están facultados para ejercer justicia penal universal frente a graves delitos como el genocidio, los delitos de lesa humanidad, los crímenes de guerra y, si no lo hacen, tienen el deber de extraditar personas a Estados que si están dispuestos a ejercer dicha jurisdicción universal. Sin embargo, hoy no se espera que el ejercicio de dicha jurisdicción penal universal sea realizado por los Estados, sino que para ello se ha establecido una institución supranacional de justicia penal internacional, como lo es la CPI. estas graves violaciones de derechos humanos (Khanna, 1999, pp.1477-1534). De hecho, allí se propone que, a nivel global, esos asuntos civiles de derechos humanos sean tratados en el arbitraje y la necesidad de incluir cláusulas de derechos humanos en los TLC y TIB, como ya lo viene haciendo la Unión Europea (Rey, 2007, p.16). De igual forma, la experiencia en litigio indica que este problema es latente, pues las jurisdicciones internas son costosas, lentas y no tienen la capacidad, la idoneidad, ni la voluntad para asumir estos asuntos.

Por ejemplo, en Colombia, algunas víctimas han recurrido a instancias internacionales como la ofrecida por los Estados Unidos, en donde las víctimas colombianas $y$ sus asesores, que han demandado a empresas de ese país y a personas extraditadas como "alias macaco", por los daños causados en la comisión de las conductas delictivas: crímenes de lesa humanidad, tortura y los crímenes de guerra (Requejo, 2011, p.24).

Además, en el sistema universal, los organismos convencionales pueden hallar responsable al Estado por la comisión de hechos contrarios a las obligaciones establecidas en los tratados internacionales. En este caso, traza recomendaciones para que se modifiquen normas y procedimientos internos que generaron la vulneración de los derechos humanos y recomienda que se pague compensación civil por los daños causados $^{17}$.

A su vez, en la doctrina de los derechos humanos se viene planteado que las personas jurídicas u organizaciones con personalidad jurídica internacional, también pueden ser responsables por las decisiones que pueden afectar los derechos humanos.

Aunque este tema es novedoso, se viene planteando que las instituciones de la ONU y de los niveles regionales también deben estar sujetas a las normas de derecho internacional de los derechos humanos. Por

17. En este sentido, la información se complementa, por ejemplo, el Caso KL VS Perú. 
ejemplo, decisiones como la implementación del régimen en la lucha contra el terrorismo en la comunidad de la ONU, sobre el que se realizó el embargo de armas y de fondos en el conflicto de Yugoslavia y que dejó en la indefensión a las otras partes frente a los Serbios y que pudo ser una de las causas del genocidio (Cfr. Ponce, 2010).

Ahora bien, en el caso de las violaciones a los derechos humanos, el derecho a la reparación de las víctimas es integral, diferenciadora y reparadora y tiene una dimensión individual, colectiva, material, moral y simbólica, por esto no se limita a la mera compensación económica sino que abarca un conjunto más amplio de medidas como la restitución, la indemnización, la rehabilitación, la satisfacción y las garantías de no repetición (ley 1448/2011) ${ }^{18}$.

\subsection{LA RESPONSABILIDAD ADMINISTRATIVA}

En materia de derechos humanos, la responsabilidad administrativa puede constituirse en una de las instancias más relevantes, debido a que está surgiendo un derecho administrativo global que resulta esencial en la gestión de los problemas globales y para la prevención de los riesgos sobre los derechos colectivos mundiales en áreas que se sustraen del dominio y regulación estatal como la construcción, internet, los contratos de libre comercio, el comercio internacional, entre otros.

En el nivel estatal, esta responsabilidad hace parte del desarrollo de instituciones muy técnicas y especializadas (por ejemplo, Superintendencias y corporaciones) en el control de actividades íntimamente asociadas a los derechos fundamentales como la educación, la salud, las políticas públicas, el riesgo financiero, el riesgo ambiental, el riesgo virtual, entre otras.

Así mismo, en las normas administrativas es donde se encuentran las normas del riesgo permitido $\mathrm{y}$ las autorizaciones

18. Esta disposición habla sobre cómo se ha estructurado la participación de la víctima en el proceso penal para su reparación ver Patiño (2009, p.229). (licencias) para el desarrollo de actividades relacionadas a los derechos fundamentales, sociales y colectivos y los deberes de prevenir.

\subsection{LA RESPONSABILIDAD PENAL}

La responsabilidad penal, tanto en el ámbito universal como estatal, está centrada en las personas individuales. Por un lado, puede ser hallada como responsable ante la Corte Penal Internacional por los delitos internacionales de lesa humanidad, genocidio, crímenes de guerra y agresión y particularmente cuando los Estados donde se cometieron estos hechos no tengan la capacidad y disposición para investigar y juzgar esos delitos. Ahora bien, uno de los grandes interrogantes es si la empresa multinacional es responsable penalmente por la violación de los derechos humanos.

Sobre lo anterior se puede afirmar que, por un lado, en el orden internacional, durante la creación del Estatuto de Roma, este tema fue discutido, sin embargo no fue consagrada dicha responsabilidad en esta jurisdicción. En el orden estatal, se cree que es posible considerar que sí se puede aplicar la responsabilidad penal en aquellos Estados donde está consagrada la responsabilidad abierta de la persona jurídica a cualquier delito como el caso de Estados Unidos y Ecuador (Comisión internacional de Juristas, 2008).

\section{LA UNIVERSIDAD Y LOS ESTUDIOS INTEGRALES DE DERECHOS HUMANOS, FUNDAMENTALES, SOCIALES Y COLECTIVOS}

Para la universidad, resulta determinante que los contenidos académicos, la extensión o proyección universitaria hacia la sociedad y la investigación, se realicen desde enfoques integrales capaces de reconstruir los problemas y las soluciones jurídicas, políticas, económicas, administrativas, gerenciales y de cooperación que requiere la realización de los derechos humanos, fundamentales sociales y colectivos. 
Para ello, se busca la realización permanente de actualizaciones de los conceptos, la fundamentación, la materialización y las responsabilidades institucionales por la afirmación o violación de estos derechos. Por ejemplo, un estudio sobre la salud busca comprender integralmente su concepto como derecho social fundamental (Arango. 2005), además de las fundamentaciones centradas en la construcción y protección de las funciones y las instituciones que se requieren para la protección de este derecho de la persona, la estructura y el funcionamiento del sistema, las capacidades reales y las limitaciones para materializar ese derecho.

Lo anterior se complementa con la materialización mediante normas constitucionales y legales y mediante políticas públicas y decisiones de las instituciones y las responsabilidades de agentes privados y públicos.

$\mathrm{Al}$ respecto y en primer lugar, la Organización Mundial de la Salud define este derecho humano desde una perspectiva amplia, ideal, discursiva y como una aspiración de la humanidad que siempre está en proceso de construcción desde la perspectiva de la universalidad, la no discriminación, la dignidad, la plenitud institucional. Para Colombia este un derecho constitucional, un derecho fundamental que tiene medidas de protección constitucionales (tutela) y legales. Por eso, es un derecho de aplicación inmediata, justiciable y que, según el caso, se puede solicitar la protección directa ante la amenaza y vulneración.

Entonces, este se define como derecho fundamental, el cual tiene un contenido esencial relacionado con la existencia y subsistencia de una persona o como parte del mínimo vital que requiere un ser humano $\mathrm{y}$ que es independiente del desarrollo económico de un Estado (Procuraduría General de la Nación, 2008, p. 9) ${ }^{19}$.

19. "Por consiguiente, conforme a la más autorizada doctrina internacional y constitucional, el derecho a la salud es un derecho humano fundamental, que aunque es de desarrollo progresivo, impone a las autoridades estatales obligaciones específicas inmediatas".
Sin embargo, la salud debe conservar y afirmar su dimensión como derecho social, esto es, adquirir la condición de derecho social fundamental, el cual no solo es justiciable para afirmarlo o cuando es denegado o amenazado, sino que, frente a necesidades concretas, se debe contar con las diferentes opciones institucionales de políticas públicas para satisfacer esa necesidad (Arango 2005).

La fundamentación del derecho fundamental a la salud se realiza de la siguiente forma: primero, se presenta la salud en un tono discursivo y como parte de la existencia y subsistencia de una persona en la sociedad y del mínimo vital corporal/mental. Por ejemplo, se afirma que el acceso amplio e integral no se limita a paliar enfermedades, sino que debe ser un sistema edificado sobre principios como la no discriminación, la transparencia, la igualdad y la inclusión de los sectores más vulnerables.

Seguidamente se analiza la estructura y funciones del sistema de la salud y las instituciones en las que están contenidos los diferentes ámbitos de la salud de la persona.

Esto es, se estudia el sistema social que se ha diferenciado con la función de reconocer $\mathrm{y}$ proteger ese derecho fundamental y en donde se comunica y se toman decisiones concretas sobre el acceso o no al sistema de salud, medicamentos, tratamientos, procedimientos, etc. Aunque las normas de derechos humanos y fundamentales no trazan un modelo ideal del sistema de la salud en materia de acceso, eficiencia y calidad, sí dan unas características básicas sobre las cuales debe ser construido este sistema, con el fin de cumplir su función social de manera legítima y eficiente.

De esta manera, es en este punto en donde se puede considerar que los derechos humanos y fundamentales sirven como un referente para proteger y fortalecer esas funciones del sistema y esas características básicas y técnicas, de eficiencia y legitimidad con las que debe operar para cumplir su 
función social de proteger y garantizar la comunicación sobre salud.

Además, la materialización del derecho a la salud se puede analizar, en un primer nivel, en la positivización como derecho humano en el sistema universal, desde el Pacto Internacional de Derechos Civiles y Políticos (artículo 7), El Pacto Internacional de Derechos Económicos Sociales y Culturales (artículo 7) y las demás convenciones donde se establece este derecho humano.

Además, a nivel regional, se encuentran la Declaración Americana de los Derechos y Deberes del Hombre (artículo 11), La Convención Americana de Derechos Humanos (artículo 26) y el Protocolo Adicional a la Convención Americana sobre PIDESC de San Salvador (Artículo 10).

Complementando lo anterior y a nivel estatal, se encuentra que la positivización se ha realizado mediante los artículos 49 y 50 de la Constitución política, mediante la jurisprudencia de la Corte Constitucional, la cual lo protegió como derecho conexo a la vida y el mínimo vital, con la aplicación en el ordenamiento jurídico colombiano, de los tratados antes mencionados (bloque de constitucionalidad) y mediante la aplicación del control de convencionalidad para ajustar el ordenamiento nacional a la Convención Americana de los Derechos Humanos y, finalmente, mediante la Ley 1751/15 y con los actos administrativos que desarrollan la ley.

Ahora bien, la materialización, mediante la política pública de salud, se inicia con la Ley $100 / 93$ y, en la actualidad, existen diversos subsistemas como la prevención, la gestión de la salud, el acceso universal al sistema, los sistemas de calidad, la financiación, los medicamentos, los planes regionales y sectoriales de poblaciones, etc. En ese orden, la metodología de las políticas públicas sirve para analizar y construir, tanto los problemas generales como concretos, que pueden obstaculizar o donde se elaboran y comunican decisiones que deniegan el servicio y las funciones del sistema de salud.
Como se ha dicho, más allá de las normas constitucionales y legales, mediante esta metodología se pueden analizar los procedimientos y políticas desarrollados por las instituciones y las decisiones o no decisiones que afectan el acceso al derecho fundamental. Por eso, el análisis de la política pública reconstruye los problemas concretos que afectan la implementación de esas medidas, no solamente el desarrollo normativo, sino principalmente el conjunto de acciones, medidas y programas que deben ser implementadas en cada institución IPS, EPS, clínica u hospital y los órganos y personas responsables de decidir sobre los mismos.

En cuanto a la financiación del sistema y el manejo transparente de los recursos de la salud, se encuentra, por ejemplo, la Ley 1122/2007, la cual crea el Sistema de Inspección, Vigilancia y Control del Sistema General de Seguridad Social en Salud, en cabeza de la Superintendencia Nacional de Salud, y cuyos ejes de trabajo son: el financiamiento, el aseguramiento, la prestación de servicios de atención en salud pública, la atención al usuario, la participación social, las acciones y medidas especiales, la información y la focalización de los subsidios en salud.

Por su parte, la ley 1474 de 2011 o Estatuto Anticorrupción, en el artículo 12 establece el Sistema Preventivo de Prácticas Riesgosas Financieras y de Atención en Salud del SGSSS y ordena a la Superintendencia que defina los sujetos, objeto de la vigilancia, el conjunto de medidas preventivas que deben implementar y los indicadores de alerta temprana y como debe ejercer sus funciones de control.

En el artículo 6 del Decreto 2462 de 2013, que modifica la estructura de la Superintendencia de Salud, se establece que una de las funciones es la inspección, vigilancia y control al FOSYGA, y a quienes administren recursos de la Salud, incluyendo las normas técnicas, científicas, administrativas y financieras del Sector Salud". 
De otro lado, la Ley 1753 de 2015 (art. 66), "Plan Nacional de Desarrollo 20142018, dispuso la creación de la Entidad Administradora de los Recursos del Sistema General de Seguridad Social en Salud (SGSSS) que se denomina ADRES.

Así, el sistema "Preventivo de Prácticas Riesgosas Financieras", que fue fortalecido mediante el Decreto 2462 de 2013 y modifica la estructura de la Superintendencia, creando la Oficina de Metodologías de Supervisión y Análisis de Riesgo, así como el cargo de Superintendente Delegado para la Supervisión de Riesgos con funciones de vigilancia, recolección y análisis de información relevante para la aplicación de la Sistema Basado en Riesgo mediante la identificación y prevención de riesgos y la incorporación de alertas tempranas.

Así mismo, mediante la resolución 4559 de 2018, "se adopta el modelo de Inspección, Vigilancia y Control de la Superintendencia para el ejercicio de la supervisión de los riesgos inherentes al Sistema General de Seguridad Social en Salud". En esta norma (artículo 2), se exige que las entidades vigiladas implementen un sistema integrado de gestión de riesgos y los mecanismos para hacer exigible el sistema para cada tipo de entidad vigilada, con las instrucciones con los lineamientos mínimos que debe tener.

Finalmente, la Circular Externa 0006 de 2018 indica que esos sistemas de gestión deben ser implementados por el representante legal, la Alta Gerencia a través de la Junta Directiva, administradores, directores, jefes de oficina o quienes hagan sus veces y demás funcionarios responsables de la administración de dicha entidad ${ }^{20}$.

\section{CONCLUSIONES}

1. No existe una definición única de lo que son los derechos humanos y fundamentales, sino distintos conceptos filosóficos, sociológicos, económicos y jurídicos en los que se combina la naturaleza ideológica, metafísica y trascendental, con la definición material, práctica y de las necesidades humanas en la sociedad moderna.

2. Con los acelerados cambios en las relaciones sociales globales, han surgido nuevos ámbitos donde se requiere argumentar, con buenas razones, porque son asuntos de derechos humanos (internet, producción de alimentos y medicamentos, entre otros), ahora bien, en otros ámbitos tradicionales como la dignidad y el buen nombre surgen nuevas relaciones que también requieren fundamentaciones adicionales de derechos humanos y fundamentales.

3. La materialización de los derechos humanos ya no está asociada a la consagración de normas universales o estatales (derechos constitucionales), sino que se requieren acciones y decisiones concretas de políticas públicas, de las propias empresas y de personas dirigidas a prevenir y respetar esos derechos. De acuerdo con esto, la gobernanza social contemporánea indica que la solución de los problemas de derechos humanos no solamente son un asunto que compete a los actores públicos, sino que se requiere de la cooperación pública y privada.

4. El estudio de las responsabilidades, en materia de derechos humanos, se ha vuelto un asunto práctico y de litigio estratégico en áreas como el derecho civil, administrativo y penal, porque en ellas se involucran las organizaciones de defensores de derechos humanos y los grupos de investigación de las universidades.

5. Como se ha visto con el ejemplo del derecho fundamental a la salud, la Universidad puede realizar grandes estudios, aportes, propuestas de política pública y de litigios dirigidos a realizar transformaciones del sistema y diagnósticos de este tipo, que permitan dar solución a los problemas que impiden la materialización de este derecho fundamental en Colombia.

20. La información se puede complementar y consultar en el siguiente enlace: https://www.supersalud.gov.co/ es-co/normatividad/circulares-externas 


\section{REFERENCIAS}

» Acceso a la Justicia: Casos de Abusos de Derechos Humanos por Parte de Empresas. Colombia, Comisión Internacional de Juristas, 2010.

» Alexy, Robert, (1998). La fundamentación de los derechos humanos en Carlos Nino. En: Doxa: Cuadernos de Filosofía del Derecho, № 42, 1998, p. 1743-203.

» Alexy, R. (2000). La Institucionalización de los derechos humanos en el estado constitucional democrático. En: Revista Derechos y Libertades: Revista del Instituto Bartolomé de las Casas, Valencia, 2000, pp. 21-4231.

»Ambos, Kai, (2000). Sobre el Fundamento Jurídico de la Corte penal Internacional. Un análisis del Estatuto de Roma. En: Revista de Derecho Penal y Criminología, 2 época $\mathrm{N}^{\circ} 5,2000$, pp. 14127-169.

» Ángel, N. (2008). La discusión en torno a las soluciones de soft law en materia de responsabilidad social empresarial. En: Revista de derecho privado $\mathrm{N}^{\circ} 40$, U. Andes, 2008, pp. 3-37.

» Arango Rodolfo, (2005). El concepto de derechos sociales fundamentales U. Nacional, Legis, p.p. 1- 380.

» Arango, R. (2007). El derecho a la salud en la jurisprudencia constitucional. En: Teoría constitucional y políticas públicas, U. Externado.

» Bernal, C. (2007). Democracia y globalización en América Latina. En: El derecho en el contexto de la globalización, U. Externado.

» Bernal, PULIDO Carlos, (2010). La metafísica de los derechos humanos. En: Revista Derecho del Estado, № 25, 2010, pp. 117-133 y s.s.

» Bobbio, Norberto, (1991). El tiempo de los derechos. Ed. Sistema, Madrid.

» Botero, C. y Guzmán, D. (2007). El sistema de los derechos, guía práctica del sistema internacional de protección de los derechos humanos, Dejusticia.

» Castro, L. (2014). Fragmentación, Soft law y sistema de fuentes del derecho internacional de los derechos humanos, U. Nacional.

» CIDH. (s.f.) Control de Convencionalidad. Cuadernillos de jurisprudencia de la $\mathrm{CIDH}$.

» Comisión internacional de juristas. (2008). Complicidad empresarial y responsabilidad legal. Derecho penal y crímenes internacionales, Vol. II.

" Comisión Intersectorial de Alertas Tempranas. (2012). Metodología para la valoración de los riesgos de violaciones de derechos humanos e infracciones del DIH.

» Compliance. (2017) Guía práctica de identificación, análisis y evaluación del riesgo. Aranzadi.

» Cortés, F. (2007). ¿Hay un conflicto insuperable entre la soberanía de los Estados y la protección de los derechos humanos? En: Cortés F, Giusti M, compiladores. Justicia global, derechos humanos y responsabilidad. Bogotá: Siglo del Hombre Editores. Universidad de Antioquia y Universidad Católica del Perú, pp. 135-163. Defensoría del Pueblo. (2013). La Tutela y el derecho a la salud 2012.

» Di John, J. (2010). Conceptualización de las causas y consecuencias de los Estados fallidos: Una reseña crítica de la literatura. En: Revista de Estudios Sociales, $\mathrm{N}^{\circ}$ 37, U. Andes, pp. 46-86. 
» Díaz, M. (2002). Globalización y principio de jurisdicción universal: Un estudio de caso. En: Boletín mexicano de derecho comparado, Año 35, № 105.

» Fariñas, M. (1998). Los derechos humanos desde una perspectiva sociojurídica. En: Revista Derechos y Libertades: Revista del Instituto Bartolomé de las Casas, $\mathrm{N}^{\circ}$ 3, pp. 355-376.

» Fariñas, M. (1998a). Sociología de los derechos humanos. En: Derecho y Sociedad, Valencia, Tirant lo Blanch, pp. 687-701.

» Gómez, C. y Corominas, T. (2017). Programas de compliance para partidos políticos. Compliance en la administración pública. En: Manual práctico de compliance, Civitas-Thomson Reuters, pp. 169-191.

» Gonzales, F. y Rettberg, A. (2010). Pensando la fragilidad estatal en Colombia. En: Revista de Estudios Sociales, № 37, U. Andes, pp. 131-137.

» Habermas, J. (1994). Derechos humanos y soberanía popular: las concepciones liberal y republicana. En: Derechos y libertades, Revista del Instituto Bartolomé de las casas, año 2 , $n^{\circ} 3$, pp. 215-230.

» Hart, H. L. A. (1955). Are There Any Natural Rights? En: The Philosophical Review, Vol. 64, No. 2, pp. 175-191.

» Isaza, J. (2011). Inducción a la responsabilidad civil. CSJ, EJRLB.

» Jaramillo, J. y Castro, L. La ejecución interna de las decisiones de los órganos internacionales de protección de los derechos humanos. El caso Colombiano. En: Derecho internacional de los derechos humanos y sistemas internos de protección y reparación, Min Relaciones Exteriores- U. Nacional de Colombia.

» Kaufmann, A. (1998). La universalidad de los derechos humanos. Un ensayo de fundamentación. En: Revista persona y sociedad, U. Navarra, N 38, pp. 11-34.

» Khanna, V. (1999). Corporate criminal liability: What purpose does it serve? En: Harvard Law Review, Volume 109, № 7, pp. 1477-1534.

» Lozano, Vivian, (2004). La evolución de los derechos humanos: El proceso de positivización. En: Revista Derecho del Estado, N 16, U. Externado, pp. 1651762004

» Luhmann, N. (1993). El Derecho de la sociedad. Herder. U. Iberoamericana.

» Luhmann, N. (2010). Los derechos fundamentales como institución. Aportación a la sociología política. U. Iberoamericana.

» Manual práctico de compliance (2017) Civitas-Thomson Reuters.

» Martin, O. (2008). Empresas multinacionales y derechos humanos en derecho internacional. Bosch.

» Nassehi, A. (2005) La diferencia de la comunicación y la comunicación de la diferencia: Sobre los fundamentos de la teoría de la comunicación en la teoría social de Niklas Luhmann. En: Teoría de sistemas y derecho penal, Comares, pp. 21-40.

» Newman, Vivian, y Ángel, María Paula, (2019). Rendición de cuentas de Google y otros negocios en Colombia: la protección de datos personales en la era digital. Dejusticia, 2019., p.p. 1- 117.

$»$ Nino, C. (1988). Constructivismo epistemológico: Entre Rawls y Habermas. En: Doxa Cuadernos de Filosofía del Derecho, N 5, pp. 87-105 
Nino, C. (1989). El constructivismo ético. CEE, Madrid.

» Nino, Carlos (1998), Constructivismo epistemológico: Entre Rawls y Habermas. En: Doxa: Cuadernos de Filosofía del Derecho, Doxa, N 5, 1998, p. 987-105.

» Papachini, A.ngelo, (1994). Filosofía y derechos humanos. Cali, Editorial Universidad del Valle.

» Parra, O. (2003). El derecho a la salud en la constitución, la jurisprudencia y los instrumentos internacionales. Defensoría del Pueblo.

» Patiño, M. (2009). La intervención procesal de la víctima, U. Nacional.

» Pérez, A. E. (1983). La fundamentación de los derechos humanos. En: $R e-$ vista de Estudios Políticos (Nueva Época), Núm. 35. Septiembre-Octubre, 1983, p.

7-7213.

» Pérez, A. E. (1993). El concepto de los derechos humanos y su problemática actual. En: Derechos y Libertades: Revista del Instituto Bartolomé de las Casas, Año $1, \mathrm{~N}^{\circ} 1$, pp. $179-19683$.

» Pérez, L., Botero, J. Estándares del diseño de una política pública de prevención de violaciones de derechos humanos e infracciones al DIH. Usaid, U., Andes, 2012.

» Pogge, T. (2008). Reconocidos y violados por la ley internacional: los derechos humanos de los pobres globales. En: Justicia global, derechos humanos y responsabilidad. Siglo del hombre. U. Antioquia, U. Católica del Perú.

» Ponce, E. (2010). Violación de derechos humanos y de normas imperativas de derecho internacional en la lucha contra el terrorismo por parte del Consejo de Seguridad de las Naciones Unidas. En: Revista de derecho público, $\mathrm{N}^{\circ} 24, \mathrm{U}$. Andes, pp. 1-30.

» Presidencia de la República. (2014). Lineamientos para una política pública de Derechos Humanos y empresas, Programa Presidencial de Derechos humanos.

» Procuraduría General de la Nación. (2008). El derecho a la salud en perspectiva de derechos humanos y el sistema de Inspección, Vigilancia y Control del Estado Colombiano en Materia de Quejas en Salud. Procuraduría General de la Nación, Dejusticia, Agencia Catalana de Cooperación y Desarrollo. 2008, p.p. 1- 219

» Ramelli, A.lejandro, (2011). Jurisprudencia penal internacional aplicable en Colombia. U. Andes, GIZ. 2011, p.p. 469 y 470.

» Ramírez, G. (2009). Pobreza globalización y derecho: ámbitos global, internacional y regional de regulación. U. Externado.

» Rawls, J. (1979). La teoría de la justicia. FCE, México.

» Rawls, J. (1996). El derecho de los pueblos. U. Andes.

» Requejo, M. (2011). La responsabilidad de las empresas por violaciones de derechos humanos deficiencias de marco legal. En: Scientia juris.

» Rey, P. (2007). El arbitraje de inversiones y los retos de la globalización. En: Revista de derecho privado, $\mathrm{N}^{\circ} 38$, U. Andes.

» Rodríguez, C. (2013). Investigación anfibia: la investigación-acción en un mundo multimedia, Bogotá, Dejusticia. 
» Stiglitz, J. (2008). Is there a Post-Washington Consensus Consensus? En: The Washington Consensus Reconsidered. Towards a New Global Governance, Oxford U.

» Teubner, G. (2005). Sociedad global, justicia fragmentada. Sobre la violación de los derechos humanos por actores trasnacionales privados. En: Derecho y justicia en la sociedad global, Anales de la Cátedra Francisco Suarez, № 39, U. Granada, pp. 551-596.

» Uprimny, R. (2008). Una introducción al derecho internacional de los derechos humanos y a su sistema de fuentes. En: Derecho Internacional de los DDHH y sistemas internos de protección y reparación, U. Nacional, Min Relaciones Exteriores.

» Uprimny, R. y Rodríguez C. (2007). Constitución, modelo económico y políticas públicas en Colombia: El caso de la gratuidad de la educación primaria. En: Los derechos sociales en serio: hacia un diálogo entre derechos y políticas públicas. Bogotá. Centro de Estudios de Derecho, Justicia y Sociedad, DeJusticia.

» Uprimny, R., Uprimny, M. y Parra, O. (2006). Derechos humanos y derecho internacional humanitario. Consejo Superior de la Judicatura, Escuela Judicial "Rodrigo Lara Bonilla". Enero 2006.

» Vicepresidencia. (2010). Formación Especializada en Investigación, Juzgamiento y Sanción de Violaciones a los Derechos Humanos e Infracciones al Derecho Internacional Humanitario III. 